\title{
Magnitude and associated factors of hypertension in Addis Ababa public health facilities, Ethiopia
}

\begin{abstract}
Background: According to WHO's world health report in 2008 13\% of the global death attributed by raised blood pressure. The Objective of the study was to assess the prevalence and associated factors of hypertension in Addis Ababa public health facilities.

Methodology: Cross-sectional study design was used to assess the prevalence and associated risk factors of hypertension in Addis Ababa public health facilities. A total of 758 participants were selected by using simple random sampling. WHO STEPS wise approach to surveillance of NCDS risk factors was used to collect the data. The result was analyzed using SPSS program and descriptive summary using frequencies, proportions, graphs and cross tabs was used to present study results. Bivariate and multivariate logistic regression analyses were conducted to identify determinant factors.
\end{abstract}

Result: The overall prevalence of overweight was $47 \%$ with $36.7 \%$ and $10.8 \%$ of the participants were overweight and obese respectively. The prevalence of hypertension in the study area was also high, which affected $32.3 \%$ from the total participants. Sex, marital status, age, educational status, occupation, history of alcohol consumption, BMI and physical activity, lipid profiles had significant statistical association with hypertension.

Conclusion and recommendation: the prevalence of hypertension in the study area was high and the lifestyles and socio-demographic characteristics of the study participants were the risk factors associated with the development of hypertension and diabetes mellitus. Improving healthy lifestyles of the population should be strengthening to prevent hypertension.

Keywords: hypertension, associated factors, BMI, overweight, obesity
Volume 7 Issue 6 - 2018

\author{
Getabalew Endazenaw Bekele,' Trhas \\ Tadesse, ' Roman Negaw,' Taye Zewde² \\ 'Department of social and population health, Yekatit 12 Medica \\ College, Ethiopia \\ ${ }^{2}$ Department of biochemistry, Yekatit 12 Medical College, \\ Ethiopia
}

Correspondence: Getabalew Endazenaw, Bekele,Yekatit 12 hospital medical college, Ethiopia, Tel +25I-91 I570138, Email eyobgatabalew@gmail.com

Received: October 26, 2018 | Published: November 23, 2018

\section{Introduction}

World health organization reported that non communicable diseases are the leading causes of death globally. Mainly cardiovascular diseases, cancers, chronic respiratory diseases and diabetes represent a leading threat to human health and development. These four diseases are the world's biggest killers, causing an estimated 35 million deaths each year - $60 \%$ of all deaths globally-with $80 \%$ in low- and middleincome countries. ${ }^{1}$ According to literature most people who live in urban are more affected by hypertension. These diseases are also more commonly affect the population who rarely eat fruit and vegetables than who frequently consume fruit and vegetables. ${ }^{2}$ Hypertension and diabetes are higher in males than women and among individuals who have high BMI and waist circumference. ${ }^{3}$ According to the study done in England the prevalence of hypertension was $31 \%$ and $28 \%$ among males and females respectively with increasing prevalence by the age of the population in both sexes. ${ }^{4} \mathrm{~A}$ large-scale prevalence study of hypertension in the elderly population of the sub-Saharan Africa (SSA) reported prevalence of hypertension to be $69.9 \%$ of which 62.3 $\%$ had not been previously diagnosed this report can clearly show the case to be a large problem in the elderly population. ${ }^{5}$ In some African countries like Cameroon Community-based multicentre crosssectional study conducted by the year 2012 in major cities showed the overall prevalence of hypertension to be $47.5 \%$ which shows a higher prevalence like similar study done in Tunisia adolescents, prevalence of hypertension to be $35.1 \%$ [32.9-37.4] through a national crosssectional study. ${ }^{6}$
Cross-Sectional Surveys in Rural and Urban Communities of four Sub-Saharan Africa countries (Nigeria, Kenya, Tanzania and Namibia) reported prevalence of hypertension ranging from $19.3 \%$ in rural Nigeria to $38 \%$ in urban Namibia. ${ }^{7}$ Hypertension is now a day becomes one of the common public health problems in Ethiopia. According to the different study conducted in Ethiopia the prevalence of hypertension increased as the age of the individuals increased. For example according study done in Dabat district and Gondor town the overall prevalence of hypertension was $27.9 \%$ with increased the odd of hypertension occurrence by $6 \%$ as the age of the participants increased by one year. In this study the prevalence of hypertension was higher $(29.3 \%)$ in women than men $(23.3 \%) .{ }^{8}$ Cross-sectional studies done among adults in Addis Ababa City showed the ageadjusted prevalence of high blood pressure or reported use of antihypertensive medication to be $31.5 \%$ among males and $28.9 \%$ among females. In this study, age and BMI were significantly associated with mean systolic blood pressure and diastolic blood pressure in males and females, while educational level was inversely associated with both blood pressures in males. Current daily smoking was associated with hypertensive, while level of total physical activity was inversely associated with SBP in males. ${ }^{9}$ A cross sectional survey conducted in Sidama Zone showed the prevalence of hypertension to be $9.9 \%$. Being over 30 years, having a family history of hypertension, BMI $\geq 25 \mathrm{~kg} / \mathrm{m}^{2}$ and excess meat consumption where found to be significantly associated with hypertension whereas tea drinking was found as a protective factor for hypertension..$^{10}$ The overall prevalence of hypertension was found to be $28.3 \%$ in a community based cross 
sectional study conducted among adults in Gondar city. It was also found out that Participants who had self-reported diabetes were about four times more likely to be hypertensive. Those who did not walk at least for 10 minutes continuously on daily basis were about three times more likely to be hypertensive. Compared to those having normal BMI obese were significantly associated with hypertension. ${ }^{11}$ A community based study in the same region with this study showed the prevalence of hypertension to be $22.4 \%$. The study reported $40 \%$ of those hypertensive patients in the study were newly screened. ${ }^{12}$

\section{Methods and materials}

Study area and period-This study was conducted in Addis Ababa city Administration from March to September 2016 by using structured interviewed questionnaire. Addis Ababa city administration is one the city administration in Federal Democratic Republic of Ethiopia. The total population of the city according to the census 2007 projection is 3.65 million, of which, 1.89 million is females and 1.76 million is male. Administrational the city is divided into 10 sub-cities and 99 kebeles. The city administration has 6 hospitals and 103 health centers which give health services for the population. Study design -facility based cross-sectional study design was used to collect the data. Source population is all individuals lived in Addis Ababa city administrations that are above 18 years age and used health services in public health facilities in Addis Ababa as outpatient. Study population is all individuals used health services in selected public health facilities in Addis Ababa as outpatient and above 18 years of age.

\section{Sample size determination}

Minimum sample size was determined by using single population proportion sample size calculation formula with the assumption of $37.7 \%$ of raised blood pressure in Addis Ababa, ${ }^{13}$ a $95 \%$ confidence level $(\mathrm{Za} / 2)$, a $5 \%$ margin of error (d), multiple by the design effect of 2 and add $10 \%$ non-response rate. The total sample size was 758 persons.

\section{Sampling technique and procedure}

Multistage sampling technique was used. First from 10 sub-cities 3 sub-cities are selected randomly by using lottery method (Arada, Yeka and Kirkos). Secondly from each selected sub-cities 30\% of the hospitals (one hospital) and health centers (10 health centers) are selected randomly to get more representative participants. The required sample size was calculated and allocated to each health facilities equally. Finally to select the individual participant simple random sampling technique was used based on the card number.

\section{Data collection}

A structured pretested questionnaire which was derived from WHO STEPS wise approach to surveillance of NCDS risk factors was used to interview the participants. The questionnaire was divided in to two part: Part I about information on socio demographic variables of participants such as; age, sex, marital status, family history of any of the NCDs, educational level, monthly income, employment status, nature of work, work environment, area of residence and type of family. Part II about information on individual's behavioral variables. Data collection moves along a sequential three-step process as follows:

i. Step 1: Interview-based questionnaire on selected major health risk behaviors including smoking, alcohol consumption, poor fruit and vegetable consumption, and physical inactivity. ii. Step 2: Physiological measures of health risks such as height, weight, blood pressure, body mass and waist girth circumference.

The height of the participants was measured in standing erect position using standometer with $0.1 \mathrm{~cm}$ resolution. The weight of the participants was measured using beam balance with barefoot and wearing light clothes with $0.1 \mathrm{~kg}$ resolution. The waist circumference was measured using measuring tape of $0.1 \mathrm{~cm}$ resolution from midpoint between the last rib and iliac crest. Blood pressure of the participants was measured using sphygmamometer after 10 minutes rest on their left hand at sitting position and for those whose blood pressure is high second measurement was taken after 10 minutes additional rest.

iii. Step 3: Biochemical measures of health risks including blood lipids. Blood sample was taken after 8-12 hours fasting to measure lipid profile (total cholesterol, triglyceride, high density lipoprotein cholesterol (HDL-C)

\section{Data quality management}

The quality of data was ensured through using structured questionnaire first developed in English then translated into Amharic version, proper training of data collectors and pre testing of the questionnaire on $5 \%$ of the sample size ( 39 people) in health facilities which is not selected to conduct the main study and the result of the pretest was discussed \& some corrections and changes was made if necessary. As well close supervision of data collectors. All the instruments which were used in measurement and sample collection was checked for their functionality before the actual data collection every day based.

\section{Data processing and analysis}

First the data was checked for completeness and consistency. Then it was coded and entered in the computer using SPSS version 23 software for analysis; descriptive summary using frequencies, proportions, graphs and cross tabs was used to present study results. P-value less than 0.05 was consider as statistically significant. A bivariate and multivariate logistic regression analysis was conducted to identify determinant factors.

\section{Ethical consideration}

Ethical clearance was obtained from Yekatit 12 hospital medical college and Addis Ababa Health Bureau IRB as well a formal letter was prepared and submitted to the selected health facilities to get their permission. Verbal consent was obtained from each selected participant to confirm willingness. Honest explanation of the survey purpose, description of the benefits and an offer to answer all inquiries was made to the respondents. Also affirmation that they are free to withdraw consent and to discontinue participation without any form of prejudice was made. Privacy and confidentiality of collected information was ensured throughout the process.

\section{Results}

This research involved 758 individuals that make the response rate $100 \%$. The majority $(58.3 \%)$ of the participants were female. More than half $(57.3 \%)$ of the participants were married and $26.1 \%$ of them were single in marital status. Regarding the age of the participants ranges from 19 to 96 years of old with the mean age of $43 \pm 14$ SD. The distribution of age of the participants was $10.4 \%, 19.1 \%, 22.0 \%$ and $17.2 \%$ in the group of $19-25$ years, $33-39$ years, $40-46$ years and 54-60 years of age respectively. More than $35 \%$ of the participant's 
educational status was vocational/college/university while $15.3 \%$ of the participants were illiterate. Among the total participants $27.4 \%$ of the participants were government employed, $29.7 \%$ private workers, $34.7 \%$ were unemployed (Table 1). Among the total participants, $5.9 \%$ of the participants were smokers and $10.9 \%$ and $24.3 \%$ participants had exposed to smokers in their home and working area respectively. Regarding alcohol consumption history of the study participants, $33.6 \%$ of the study participants were current drinkers. Among those who drank alcohol $18.8 \%$ of the participants were drank alcohol 5-7 days per week whereas $20.1 \%$ of them drank less than once per month. The majorities (49\%) of the participants were drank 1-3 standards of alcohol and $6.7 \%$ of them drank more than 5 standards of alcohol within single occasion. The large amount consumed by the participants in single occasion, among those who drank alcohol $61.6 \%$ of them were drank $5-10$ standards of alcohol and $4.7 \%$ of the participants were drank more than 10 standards of alcohol (Table 2).

Table I The distribution of socio-demographic characteristics of the participant in Addis Ababa December, 20 I6. N=758

\begin{tabular}{|c|c|c|}
\hline Variables & Frequency & Percent \\
\hline \multicolumn{3}{|l|}{ Sex } \\
\hline Male & 316 & 41.7 \\
\hline Female & 442 & 58.3 \\
\hline \multicolumn{3}{|l|}{ Age in years } \\
\hline $19-25$ & 79 & 10.4 \\
\hline $26-32$ & 87 & 11.5 \\
\hline $33-39$ & 145 & 19.1 \\
\hline $40-46$ & 167 & 22 \\
\hline $47-53$ & 130 & 17.2 \\
\hline $54-60$ & 65 & 8.6 \\
\hline$>60$ & 85 & 11.2 \\
\hline \multicolumn{3}{|l|}{ Marital status } \\
\hline Single & 198 & 26.1 \\
\hline Married & 434 & 57.3 \\
\hline Widowed & 87 & 11.5 \\
\hline Divorced & 39 & 5.1 \\
\hline \multicolumn{3}{|l|}{ Educational status } \\
\hline Illiterate & 116 & 15.3 \\
\hline Primary & 163 & 21.5 \\
\hline Secondary & 211 & 27.8 \\
\hline Vocational/College/University & 268 & 35.4 \\
\hline \multicolumn{3}{|l|}{ Occupation } \\
\hline Governmental employee & 208 & 27.4 \\
\hline NGO employee & 44 & 5.8 \\
\hline Private & 225 & 29.7 \\
\hline Unemployed & 263 & 34.7 \\
\hline Daily labor & 18 & 2.4 \\
\hline
\end{tabular}


Table 2 Lifestyle patterns of the study participants in Addis Ababa, December 2016

\begin{tabular}{|c|c|c|}
\hline Variables & Frequency & Percent \\
\hline \multicolumn{3}{|l|}{ History of smoking } \\
\hline Yes & 45 & 5.9 \\
\hline No & 713 & 94.1 \\
\hline \multicolumn{3}{|c|}{ Exposure to smoking in the home } \\
\hline Yes & 83 & 10.9 \\
\hline No & 675 & 89.1 \\
\hline \multicolumn{3}{|c|}{ Exposure to smoking outside the home } \\
\hline Yes & 184 & 24.3 \\
\hline No & 574 & 75.7 \\
\hline \multicolumn{3}{|c|}{ Alcohol drinking experience } \\
\hline Yes & 255 & 33.6 \\
\hline No & 503 & 66.4 \\
\hline \multicolumn{3}{|c|}{ Frequency of alcohol drinking } \\
\hline 5-7days/week & 48 & 18.8 \\
\hline I-4 days/week & 73 & 28.6 \\
\hline I-3 days/month & 83 & 32.5 \\
\hline Less than once/month & 51 & 20.1 \\
\hline \multicolumn{3}{|c|}{$\begin{array}{l}\text { Amount of alcohol consumed at single } \\
\text { occasions }\end{array}$} \\
\hline I-3 standard of alcohol & 125 & 49 \\
\hline 4-5 standard of alcohol & 113 & 44.3 \\
\hline$>5$ standard of alcohol & 17 & 6.7 \\
\hline \multicolumn{3}{|c|}{$\begin{array}{l}\text { Larger amount of alcohol consumed at } \\
\text { single occasions }\end{array}$} \\
\hline I-4 standard of alcohol & 86 & 33.7 \\
\hline 5-10 standard of alcohol & 157 & 61.6 \\
\hline$>10$ standard of alcohol & 12 & 4.7 \\
\hline \multicolumn{3}{|l|}{ Vagarious physical activity } \\
\hline Yes & 145 & 19.1 \\
\hline No & 613 & 80.9 \\
\hline \multicolumn{3}{|c|}{$\begin{array}{l}\text { Average hours spent for Vagarious physical } \\
\text { activity per week }\end{array}$} \\
\hline I-3 hours & 26 & 17.9 \\
\hline 4-6 hours & 67 & 46.2 \\
\hline 7 or more hours & 52 & 35.9 \\
\hline \multicolumn{3}{|l|}{ Moderate physical activity } \\
\hline Yes & 450 & 59.4 \\
\hline No & 308 & 40.6 \\
\hline \multicolumn{3}{|c|}{$\begin{array}{l}\text { Average hours spent for moderate physical } \\
\text { activity per week }\end{array}$} \\
\hline I-3 hours & 103 & 22.9 \\
\hline 4-6 hours & 209 & 46.4 \\
\hline 7 or more hours & 138 & 30.7 \\
\hline
\end{tabular}

Regarding the physical activity habit, the majorities of the participants were participated in vagarious and moderate physical activity. Among the total participants $19.1 \%$ and $59.4 \%$ were involved in vagarious and moderate physical activity respectively. Among those involved in vagarious physical activity, $46.2 \%$ of them spent 4-6 hours per week to perform vagarious physical and $46.4 \%$ of the participants also spent similar hours to perform moderate physical activity (Table 2). The prevalence of overweight and obesity was high. The overall prevalence of overweight was $47 \%$ with $36.7 \%$ and $10.8 \%$ of the participants were overweight and obese respectively (Table 4). Among the total female participants, $37.6 \%$ of them had waist circumference greater or equal to $80 \mathrm{~cm}$ or abdominal obesity. From male participants $28.8 \%$ the participants had waist circumference greater or equal to $80 \mathrm{~cm}$ or abdominal obesity (Fig 1). Remarkable proportion of the participants had abnormal lipid profile. Among the total study participants, $41.8 \%$ of them had total plasma cholesterol greater or equal to $200 \mathrm{mg} / \mathrm{dl}$. Similarly $41.2 \%$ and $33.9 \%$ of the participants had plasma triglyceride level greater or equal to $130 \mathrm{mg} / \mathrm{dl}$ and plasma HDL-C less than $40 \mathrm{mg} / \mathrm{dl}$ respectively (Table 3). The prevalence of hypertension in the study area was also high, which affected $32.3 \%$ from the total participants. The prevalence of hypertension was slightly higher in female participants than male participants (Table 4). To identify associated factors with hypertension bivariate and multivariate analysis was done. Based on the findings of bivariate analysis sex, marital status, age, educational status, occupation, history of alcohol consumption, high FBG level, BMI and physical activity had significant statistical association with hypertension. Female participants were $27 \%$ less risk to develop hypertension. The prevalence of hypertension increase with the age of the study participants, the participants in the age group of 26-32 years and 33-39 years of age were 6.16 times and 12.25 times more likely at risk to develop hypertension when compared to participants in the age group of 19-15 years of age respectively. Participants who had vocational/ college/university educational status was $53 \%$ less likely to develop hypertension when compared to illiterate participants. Unemployed participants were 1.91 times more likely develop hypertension when compared with governmental employed. Those who had alcohol drinking experience were 1.98 times more likely affected by hypertension when compared to their counterparts. Overweight and obese participants were 3.48 and 3.99 times more likely develop hypertension when compared to participants who had normal BMI (Table 5).

Table 3 The pattern of BMI and lipid profile of the study participants in Addis Ababa, December 2016

\begin{tabular}{lll}
\hline Variables & Frequency & Percent \\
\hline BMl & & \\
$\leq 24.9$ & 402 & 53 \\
$25-29.9$ & 274 & 36.2 \\
$\geq 30$ & 82 & 10.8 \\
Total cholesterol & & \\
$<200 \mathrm{mg} / \mathrm{dl}$ & 441 & 58.2 \\
$\geq 200 \mathrm{mg} / \mathrm{dl}$ & 317 & 41.8 \\
Triglyceride & & \\
$<130 \mathrm{mg} / \mathrm{dl}$ & 446 & 58.8
\end{tabular}


Table continued...

\begin{tabular}{lll}
\hline Variables & Frequency & Percent \\
\hline$\geq 130 \mathrm{mg} / \mathrm{dl}$ & 312 & 41.2 \\
$\mathrm{HDL}$ & & \\
$<40$ & 257 & 33.9 \\
$\geq 40$ & 501 & 66.1 \\
\hline
\end{tabular}

Table 4 Distribution hypertension by sex of the study participants in Addis Ababa, December 2016

\begin{tabular}{llll}
\hline \multirow{2}{*}{ Hypertension } & Sex & & \\
& Male & Female & Total \\
& No (\%) & No (\%) & No (\%) \\
\hline Yes & $115(15.2)$ & $130(17.2)$ & $245(32.4)$ \\
No & $201(26.5)$ & $312(41.2)$ & $513(67.6)$ \\
Total & $316(4 I .7)$ & $442(58.3)$ & $758(100)$ \\
\hline
\end{tabular}

Table 5 Factors associated with hypertension among study participants in Addis Ababa, December 2016

\begin{tabular}{|c|c|c|c|c|}
\hline \multirow[t]{2}{*}{ Variables } & \multicolumn{2}{|c|}{ Hypertension } & \multirow[t]{2}{*}{ COR $(95 \% \mathrm{Cl})$} & \multirow[t]{2}{*}{ AOR $(95 \% \mathrm{Cl})$} \\
\hline & Yes & No & & \\
\hline Sex & No (\%) & No (\%) & & \\
\hline Male & $115(15.2)$ & $201(26.5)$ & I & I \\
\hline Female & $130(17.2)$ & $312(4 \mid .2)$ & $0.73(0.536,0.990) *$ & $0.61(0.400,0.930) *$ \\
\hline \multicolumn{5}{|l|}{ Marital status } \\
\hline Single & $33(4.4)$ & $165(21.8)$ & 1 & I \\
\hline Married & $156(20.6)$ & $278(36.7)$ & $2.8 \mathrm{I}(1.84,4.279)^{*}$ & I.48(0.854,2.569) \\
\hline Widowed & $43(5.7)$ & $44(5.8)$ & $2.5(1.165,5.364)^{*}$ & $1.25(0.508,3.095)$ \\
\hline Divorce & $13(1.7)$ & $26(3.4)$ & $4.89(2.784,8.575)^{*}$ & $1.73(0.781,3.820)$ \\
\hline \multicolumn{5}{|l|}{ Age in year } \\
\hline $19-25$ & $2(0.3)$ & $77(10.2)$ & 1 & I \\
\hline $26-32$ & $12(1.6)$ & $75(9.9)$ & $6.16(1.333,28.458)^{*}$ & $5.38(1.138,25.466)^{*}$ \\
\hline $33-39$ & $35(4.6)$ & $110(14.5)$ & $12.25(2.86,52.454)^{*}$ & $8.28(1.845,37.169)^{*}$ \\
\hline $40-46$ & $67(8.8)$ & $100(13.2)$ & $25.80(6.127,108.6)^{*}$ & I4.56(3.227,65.73)* \\
\hline $47-53$ & $53(7.0)$ & $77(10.2)$ & $26.5(6.237,112.6)^{*}$ & $\mid 4.37(3.15|, 65.6|)^{*}$ \\
\hline $54-60$ & $28(3.7)$ & $37(4.9)$ & $29.14(6.58,128.91)^{*}$ & $12.16(2.45,60.24)^{*}$ \\
\hline$>60$ & $48(6.3)$ & $37(4.49)$ & $49.95(11.51,216.75)^{*}$ & $29.39(6.072,142.24)^{*}$ \\
\hline \multicolumn{5}{|l|}{ Education status } \\
\hline Illiterate & $50(6.6)$ & $66(8.7)$ & 1 & I \\
\hline Primary & $56(7.4)$ & $107(14.1)$ & $0.69(0.432, I .127)$ & $1.04(0.579,1.878)$ \\
\hline Secondary & $69(9.1)$ & $142(18.7)$ & $0.64 I(0.402, I .023)$ & $0.98(0.535,1.814)$ \\
\hline Vocational/College/University & $70(9.2)$ & $198(26.1)$ & $0.47(0.295,0.737)^{*}$ & $0.91(0.482, I .705)$ \\
\hline \multicolumn{5}{|l|}{ Occupation } \\
\hline Governmental employee & $53(7.3)$ & $155(20.4)$ & 1 & I \\
\hline NGO Employee & $16(2.1)$ & $28(3.7)$ & I.67(0.839,3.328) & $0.98(0.442,2.185)$ \\
\hline Private & $68(9.0)$ & $157(20.7)$ & $1.267(0.830,1.932)$ & $0.98(0.595,1.617)$ \\
\hline Daily labor & $4(0.5)$ & $14(1.8)$ & $0.84(0.263,2.65)$ & $0.66(0.168,2.612)$ \\
\hline Unemployed & 104(13.7) & $159(21.0)$ & $1.91(1.285,2.848)^{*}$ & $1.17(0.677,2.005)$ \\
\hline \multicolumn{5}{|l|}{ Alcohol drinking } \\
\hline No & $23 I(30.5)$ & $482(63.6)$ & 1 & I \\
\hline Yes & $3 \mid(4.1)$ & $14(1.8)$ & $1.98(1.135,3.454)^{*}$ & $1.21(0.558,2.619)$ \\
\hline HDL level & & & & \\
\hline
\end{tabular}




\begin{tabular}{|c|c|c|c|c|}
\hline \multirow{2}{*}{$\begin{array}{l}\text { Variables } \\
<40 \mathrm{mgg} / \mathrm{dl}\end{array}$} & \multicolumn{2}{|c|}{ Hypertension } & \multirow{2}{*}{ COR $(95 \% \mathrm{Cl})$} & \multirow{2}{*}{ AOR $(95 \% \mathrm{Cl})$} \\
\hline & $80(10.6)$ & $177(23.4)$ & & \\
\hline$\geq 40 \mathrm{mg} / \mathrm{dl}$ & $165(21.8)$ & $336(44.3)$ & $1.07(0.786,1.501)$ & I.4I $(0.937,2.118)$ \\
\hline \multicolumn{5}{|c|}{ Triglyceride level } \\
\hline$<150 \mathrm{mg} / \mathrm{dl}$ & $92(12.1)$ & $220(29.0)$ & I & 1 \\
\hline$\geq 150 \mathrm{mg} / \mathrm{dl}$ & $153(20.2)$ & $293(38.3)$ & I..25(0.914,I.706) & $1.02(0.690,1.508)$ \\
\hline \multicolumn{5}{|c|}{ Total cholesterol } \\
\hline$\geq 200 \mathrm{mg} / \mathrm{dl}$ & $96(12.7)$ & $22 \mathrm{I}(29.2)$ & 1 & 1 \\
\hline$<200 \mathrm{mg} / \mathrm{dl}$ & $149(19.7)$ & $292(38.5)$ & $0.85(0.624, I .161)$ & $0.43(0.284,0.647)^{*}$ \\
\hline \multicolumn{5}{|l|}{ FBG level } \\
\hline$<126 \mathrm{mg} / \mathrm{dl}$ & $196(25.9)$ & $450(59.4)$ & I & 1 \\
\hline$\geq 126 \mathrm{mg} / \mathrm{dl}$ & $49(6.9)$ & $63(8.3)$ & I.79(1.186,2.689)* & $1.45(0.882,2.383)$ \\
\hline \multicolumn{5}{|l|}{ BMI } \\
\hline Normal & $79(10.4)$ & $323(42.6)$ & I & 1 \\
\hline overweight & $126(16.6)$ & $148(19.5)$ & $3.48(2.473,4.90)^{*}$ & $3.11(2.096,4.622)^{*}$ \\
\hline Obesity & $40(5.3)$ & $42(5.5)$ & $3.99(2.419,6.578)^{*}$ & $4.08(2.3|9,7 .| 8 \mid)^{*}$ \\
\hline \multicolumn{5}{|c|}{ Vagarious physical activity } \\
\hline Yes & $35(4.6)$ & $110(14.5)$ & I & 1 \\
\hline No & $210(27.7)$ & $403(53.2)$ & $\mathrm{I} .64(\mathrm{I} .08 \mathrm{I}, 2.48 \mathrm{I})^{*}$ & $1.52(0.926,2.510)$ \\
\hline \multicolumn{5}{|c|}{ Moderate physical activity } \\
\hline Yes & $149(19.7)$ & $301(39.7)$ & I & 1 \\
\hline No & $96(12.7)$ & $212(28.0)$ & $0.92(0.67,1.248)$ & $0.79(0.549,1.126)$ \\
\hline
\end{tabular}

N.B.* means P-value less than 0.05

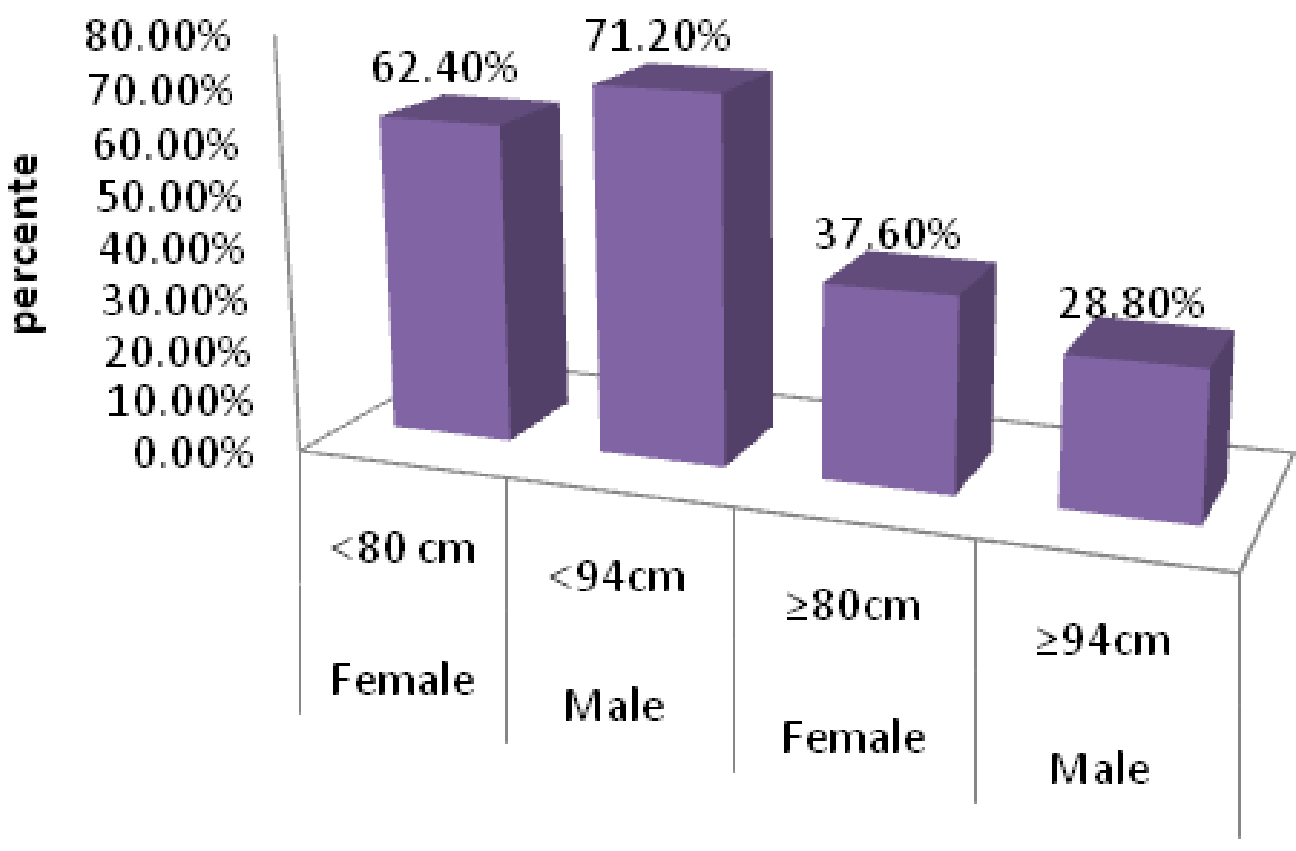

waistcercumfernce in $\mathrm{CM}$

Figure I The pattern of waist circumference among the participants in Addis Ababa December 2016. 


\section{Discussion}

This research was used to determine the prevalence and associated factors of hypertension in public health facilities in Addis Ababa city administration. More than $33 \%$ of the study participants were current drinkers and $18.8 \%$ of them were frequent drinkers. Even if the prevalence of drinking in this study was lower than the study finding done in Bishoftu it contribute a significant contribution for the occurrence of hypertension. ${ }^{14}$ In this study more than $78 \%$ of the participants had habit of physical activity (either vigorous or moderate physical activity). This finding was comparably with study done in Bisheftu in which $78.3 \%$ of the participants were physically active. ${ }^{14}$ On the hand the proportion of individuals who had physical activity habit was higher in this study when compared to previously done study in Debrebrehan referral hospital. ${ }^{15}$ The overall prevalence of overweight was $47 \%$ with $36.7 \%$ overweight and $10.8 \%$ obesity. This finding indicated overweight was the common public health problem of the society in the study area. The prevalence of overweight and obesity in this study was found higher when compared with the prevalence of overweight $(10 \%)$ and obesity $(5.3 \%)$ in the study done in Hosanna town. ${ }^{16}$ The overall prevalence of hypertension in this study was $32.3 \%$. The finding of this study was higher than the findings of previously done researches in different parts of Ethiopia. For example in Dabat district and Gondor town and Sidama zone the prevalence of hypertension was $27.9 \%$ and $9.9 \%$ respectivel $^{8-12}$ According to the finding of study done in Hosanna town $30 \%$ of the study participants were hypertensive. ${ }^{16}$ The reason for this discrepancy may be due to the variation and change in lifestyle of the population as result of study site difference and advancement of technology. In this study the prevalence of hypertension was slightly higher in women than men. This finding was comparable with the finding of study done in Dabat district and Gondor town but in contrast with the finding of study done in Addis Ababa ${ }^{8,9}$

\section{Conclusion}

The prevalence of hypertension was higher in the study area The overall prevalence of hypertension was $32.3 \%$ and $14.8 \%$ respectively. Age of the participants, alcohol consumption habit, BMI, physical activity habit of the participants, history of smoking, lipid profile of the participants were some of the factors which had statistical significant association with hypertension. The responsible body should provide health education on lifestyles and it is good to conduct analytical research to investigate why hypertension become common in this area.

\section{Acknowledgments}

We would like to express our sincere gratitude to Yekatit 12 hospital medical college to give us this prodigious chance to develop the proposal. Our special thanks also go to Addis Ababa city health office for their cooperation and assistance by giving relevant information. At last but not least we want to give our deepest gratitude for all friends who are helping us through proposal development.

\section{Conflicts of interest}

Authors declare that there is no conflicts of interest.

\section{References}

1. WHO. 2008-2013 Action Plan for the Global Strategy for the Prevention and Control of Non-communicable diseases. Geneva, Switzerland; 2008.

2. Okoduwa SI, Umar IA, Ibrahim S, et al. Socio-Economic Status of Patients with Type 2 Diabetes and Hypertension Attending the Ahmadu Bello University Teaching. Global Journal of Health Science. 2014;7(1):280-287.

3. Na L, Wu X, Feng R, et al. The Harbin Cohort Study on Diet, Nutrition and Chronic Non-Communicable Diseases: Study Design and Baseline Characteristics. PLoS ONE. 2015;10(4):e0122598.

4. Craig Knott, Jennifer, Mindell. Hypertension. The Health and Social Care Information Center; 2012.

5. Dewhurst M, Dewhurst F, Gray W, et al. The high prevalence of hypertension in rural-dwelling Tanzanian older adults and the disparity between detection, treatment and control: a rule of sixths? Journal of Human Hypertension. 2013;27:374-380.

6. Aounallah-Skhiri H, El Ati J, Traissac P, et al. Blood pressure and associated factors in a North African adolescent population. a national cross-sectional study in Tunisia. Bio Med Center public health. 2012;12:98.

7. Hendriks ME, Wit FWNM, Roos MTL, et al. Hypertension in Sub-Saharan Africa: Cross-Sectional Surveys in Four Rural and Urban Communities. PLoS One. 2012;7(3):e32638.

8. Abebe SM, Berhane Y, Worku A, et al. Prevalence and Associated Factors of Hypertension: A Crossectional Community Based Study in Northwest Ethiopia. PLoS ONE. 2015;10(4):e0125210.

9. Tesfaye, F, Byass P, Wall S. Population based prevalence of high blood pressure among adults in Addis Ababa: uncovering a silent epidemic. Bio Med Center. 2009;9(39).

10. Giday A, Tadesse B. Prevalence and determinants of hypertension in rural and urban areas of southern Ethiopia. Ethiop Med J. 2011;49(2):139-147.

11. Awoke A, Awoke T, Alemu S, et al. Prevalence and associated factors of hypertension among adults in Gondar, Northwest Ethiopia: a community based cross-sectional study. Bio Med Center Cardiovascular Disorders. 2012;12(113).

12. Paulose T, Assefa Y, Awoke A. Prevalence and Associated Factors of Hypertension among Adults in Durame Town, Southern Ethiopia. PLoS One. 2014;9(11).

13. Gunchiye Brehanu, Enquselasie Fikre. Prevalence and associated factors among workers of steel factories Akaki Kality Addis Ababa. 2014

14. Megerssa, Mistire Wolde Gebre, Samuel Kinde Birru, et al. The prevalence of undiagnosed diabetes mellitus and its risk factors in selected institutions at Bishoftu town East Shoa, Ethiopia. Journal of diabetes and metabolism. 2013.

15. Habtoweld TD, Tsega WD, Wale BY. Diabetes mellitus in outpatients in Debrebrehan referral hospital in Ethiopia. Journal of diabetes research. 2016.

16. Likawunt SA, Samuel YA, Fiseha LG. Hypertension and its associated factors in Hosanna town, Southern Ethiopia: community based cross -sectional study. BMC Res Notes. 2018:11:306. 